
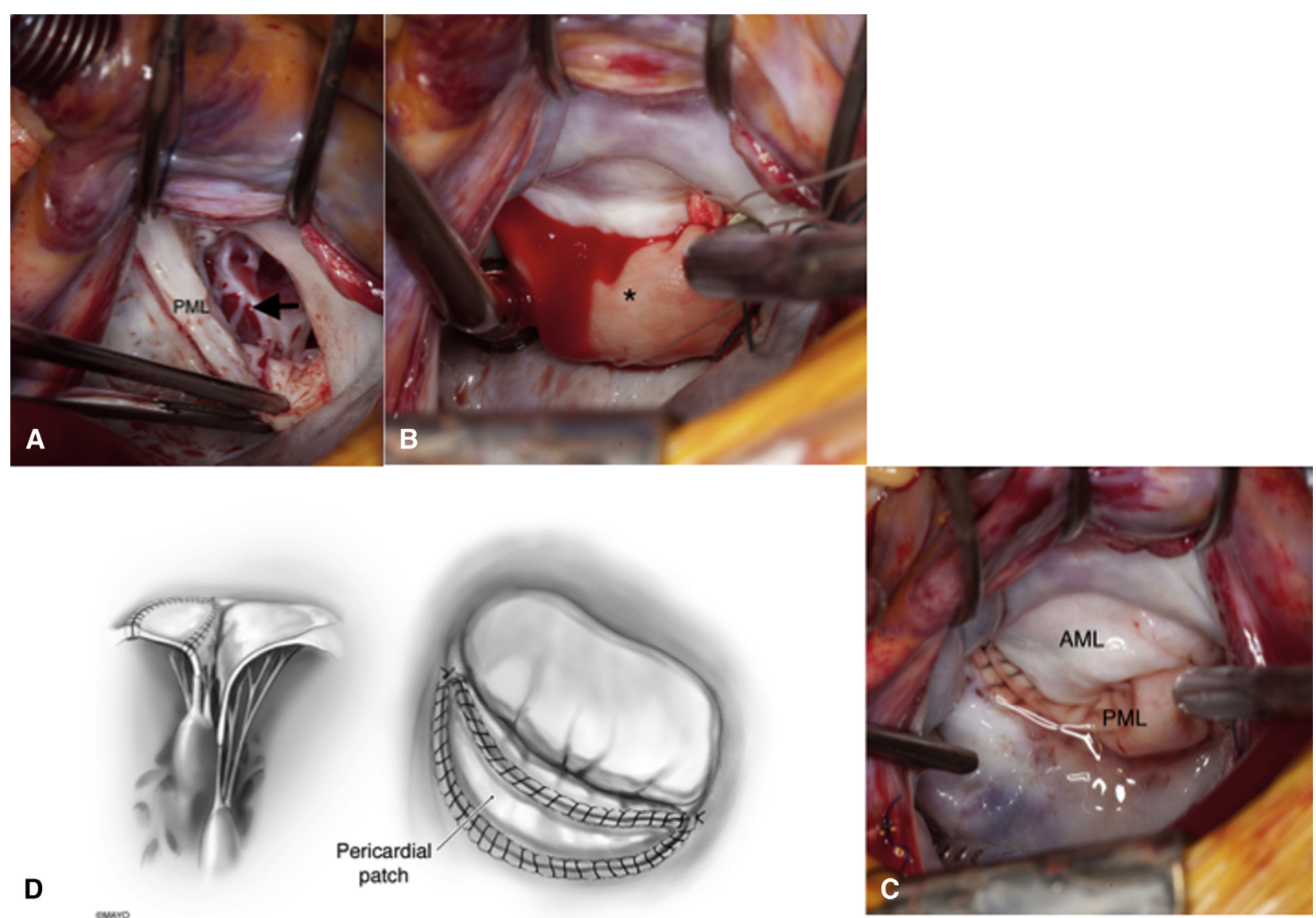

FIGURE 2. Intraoperative images and surgical repair. From the surgeon's view, the posterior mitral leaflet $(P M L)$ appears tethered as a result of severely shortened chords (A, arrow). A pericardial patch (star) is sutured circumferentially along the posterior annulus to enlarge the posterior mitral leaflet (B). Final result shows the reconstructed posterior mitral leaflet (C). The repair concept is demonstrated in the sketch (D). AML, Anterior mitral leaflet.

\title{
Magnetic resonance imaging-based management of silent cardiac rupture
}

Andrea Giuseppe Porto, MD, ${ }^{\mathrm{a}}$ Elisa McAlindon, BMBS, ${ }^{\mathrm{a}}$ Raimondo Ascione, $\mathrm{MD}, \mathrm{ChM},{ }^{\mathrm{b}}$ and Chiara Bucciarelli-Ducci, $\mathrm{MD}, \mathrm{PhD},{ }^{\mathrm{a}}$ Bristol, United Kingdom

\footnotetext{
From the Cardiology Department, ${ }^{\text {a }}$ Cardiovascular MRI Unit, and Department of Cardiac Surgery, ${ }^{b}$ Bristol Heart Institute, NIHR Cardiovascular BRU, Bristol, United Kingdom.

Disclosures: Authors have nothing to disclose with regard to commercial support.

Received for publication Oct 29, 2014; accepted for publication Nov 4, 2014; available ahead of print Dec 4, 2014.

Address for reprints: Andrea Giuseppe Porto, MD, Bristol Heart Institute, NIHR Biomedical Research Unit, Marlborough St, Bristol, BS 2 8HW, United Kingdom (E-mail: portoandrea@hotmail.it).

J Thorac Cardiovasc Surg 2015;149:e31-3

$0022-5223 / \$ 36.00$

Copyright $\odot 2015$ by The American Association for Thoracic Surgery

http://dx.doi.org/10.1016/j.jtcvs.2014.11.013
}

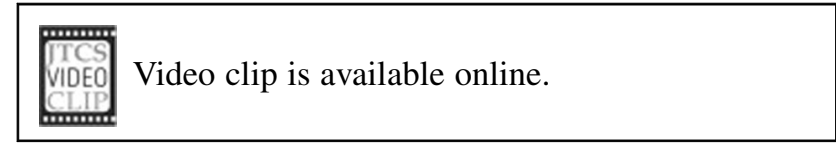

A 45-year-old man, who was a smoker, presented after recurrences of severe epigastric pain during the 2 preceding days. His electrocardiogram (ECG) showed an inferior ST elevation. Coronary angiography revealed an occluded proximal right coronary artery, which was successfully 

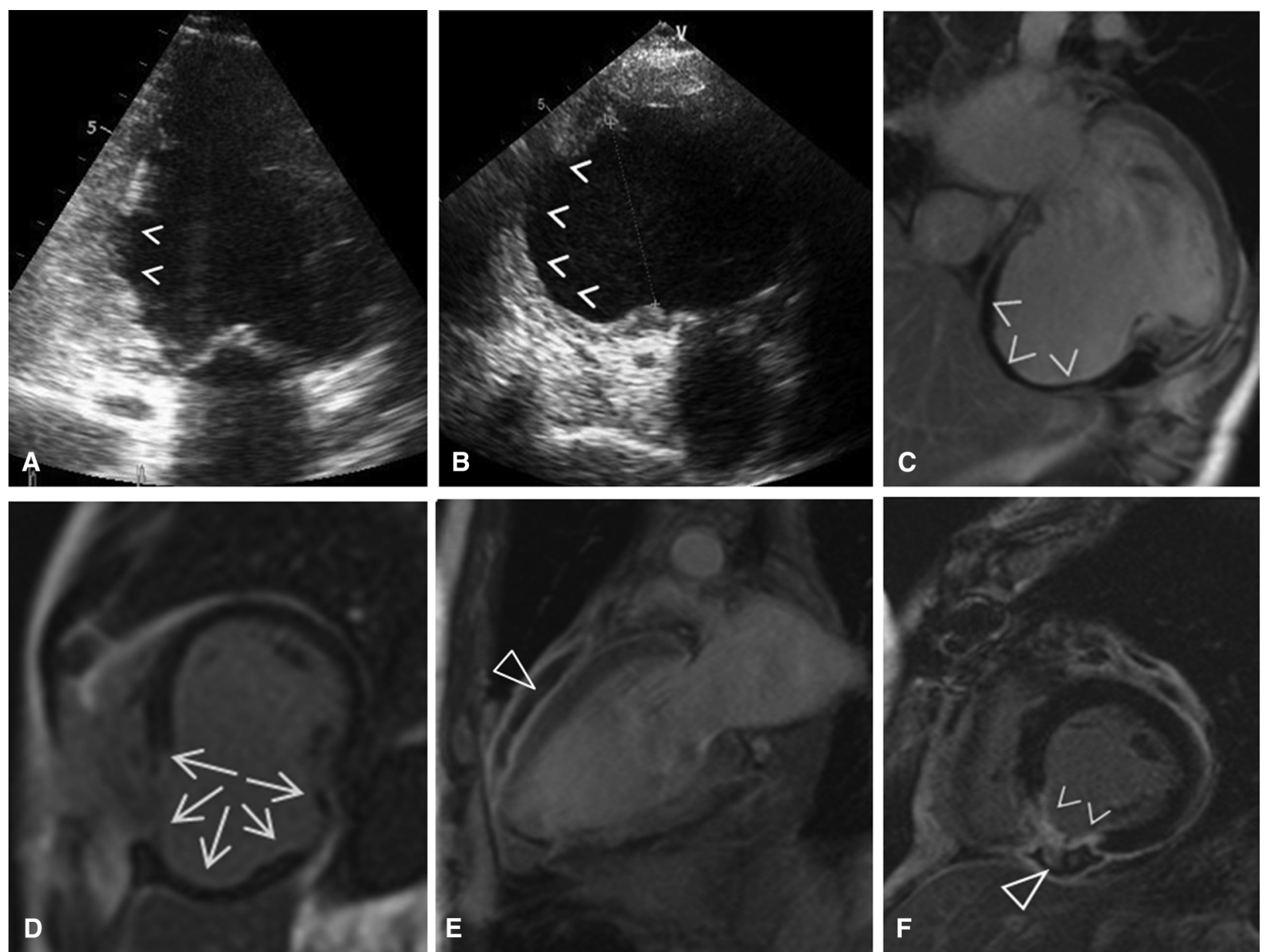

FIGURE 1. A, Transthoracic echocardiography 2 days after percutaneous coronary intervention (PCI) showing an unusual appearance of localized wall thinning and akinesia of the inferior wall of the left ventricle (arrowheads). B, Transthoracic echocardiography 6 weeks after PCI shows a severely dilated left ventricle with a large wide neck aneurysm of the inferior wall (arrowheads). C and D, CMR imaging 6 weeks after PCI. C, In the early image after contrast administration, there is evidence of a large laminar thrombus adherent to the aneurysmal cavity (arrowheads). D, The late image demonstrates a full-thickness myocardial infarction of the inferior wall (arrows). E and F, CMR imaging 3 weeks after surgical reshaping of the left ventricle. E, In the early image after contrast administration, the thrombus is no longer present. A small hematoma adherent to the anterior wall of the left ventricle is also visible (triangle). F, In the late image, the inferior infarction is still present but reduced in size (arrowheads), and the low signal structure observed represents surgical suture material (triangle).

treated with thrombus aspiration and stent deployment. However, ST-segment on ECG did not promptly resolve, lasting for up to 6 hours.

Transthoracic echocardiography 2 days after the primary percutaneous coronary intervention showed severe left ventricular (LV) systolic dysfunction with akinesia of the inferior wall enclosing a localized area of wall thinning (Figure 1, A). The patient was discharged in stable condition, symptom free, and on full medical therapy.

Transthoracic echocardiography at 6 weeks showed a severely dilated left ventricle with a large wide neck aneurysm involving the whole inferior wall with no obvious wall rupture (Figure 1, B). The patient was referred for cardiovascular magnetic resonance (CMR) imaging to further assess the underlying anatomy. CMR imaging confirmed the severe LV dysfunction (LV ejection fraction, $19 \%$ ) (Video 1), with a large aneurysm of the inferior wall and adherent laminar thrombus, best seen in contrast-enhanced images (Figure 1, C). After gadolinium administration, there was transmural myocardial infarction of the inferior wall involving the inferior papillary muscle and causing moderate functional mitral regurgitation (not shown). The images demonstrated a thin-walled $(2 \mathrm{~mm})$ rupture of the inferior wall contained by the pericardial layers (Figure 1,D).

The patient was referred for urgent surgical LV reshaping (Figure 2). A complete resection of the pseudoaneurysm and posterior ventriculoplasty inclusive of ventricular mitral valve repair was performed without complication, and the patient made a good recovery. 

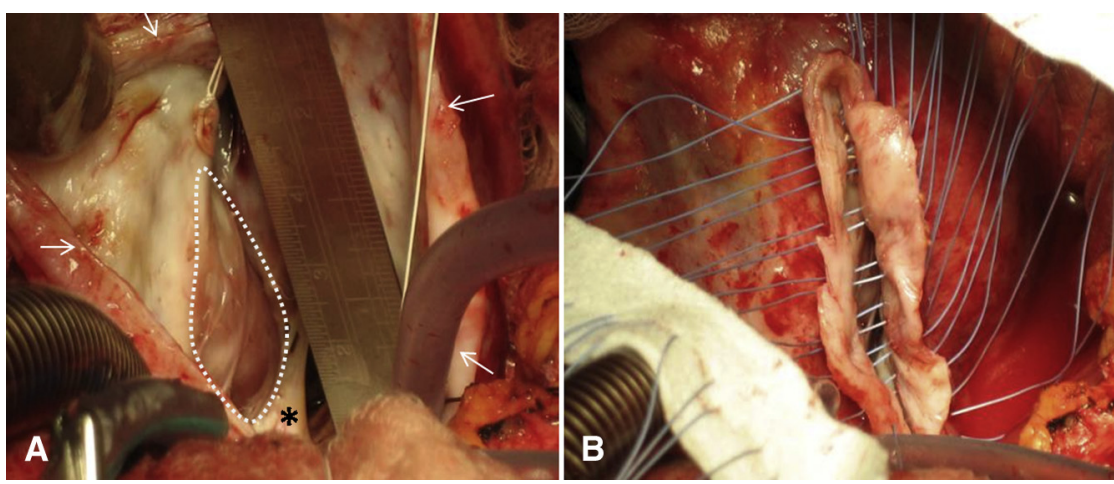

FIGURE 2. A, Surgical ventricular reshaping: The large pseudo-aneurysmal sac is opened (white arrows) and its neck reshaped (dashed line) without affecting the posterior mitral valve annulus/leaflet (black asterisk). B, The strip of nonexcised aneurysmal scar is preserved to optimize the linear closure.

Follow-up CMR imaging 3 weeks postoperatively demonstrated marked improvement with a significant reduction of $\mathrm{LV}$ volumes, an $\mathrm{LV}$ ejection fraction of $30 \%$ (Video 2), a limited residual myocardial scar in the inferior wall, and a complete resolution of the mitral regurgitation. A small pericardial hematoma and suture material in the apex also were visible (Figure 1, $E$ and $F$ ).

\section{DISCUSSION}

Cardiac rupture (CR) represents the second most common cause of in-hospital death in patients with ST-elevation myocardial infarction. ${ }^{1}$ Although the incidence of $\mathrm{CR}$ is decreasing mainly because of reperfusion therapy, ${ }^{1}$ a timely and accurate diagnosis is essential to prevent its catastrophic consequences. ${ }^{2}$

Although echocardiography represents the first-line imaging modality that can be performed at the bedside for myocardial infarction complications, CMR imaging can provide a more accurate diagnosis of the more concealed and insidious cases of CR. In the patient described in this case, ST-segment elevation persisted up to 6 hours after primary percutaneous coronary intervention, indicating impaired myocardial reperfusion despite successful restoration of the epicardial blood flow.

Considering the presence of Q-waves in the ECG at presentation, the ST-elevation also could have raised the suspicion of a subacute myocardial infarction with signs of early LV remodeling. In retrospect, it is likely that the indigestion-like pain experienced for 2 days before presentation was the beginning of the acute myocardial infarction of the inferior wall. In fact, the common innervations between the stomach and the upper abdomen ${ }^{3}$ can account for $8 \%$ of all myocardial infarctions presenting as indigestions or abdominal pain, especially inferior infarcts. This can lead to an initial misdiagnosis in $4.8 \%$ of the cases. ${ }^{4}$ In their retrospective study on CR, Baker and Koelmeyer ${ }^{5}$ reported referred pain as presentation of $\mathrm{CR}$ in $22 \%$ of cases.

In our case, the higher resolution and the unique capability of tissue characterization of CMR could better delineate the anatomy, the size and extent of myocardial scarring, and the presence of CR and intracavity thrombus, which were missed by echocardiography.

\section{CONCLUSIONS}

This case report shows CMR as a useful "heart team" tool for both diagnosis and follow-up of myocardial infarction complications. In addition, CMR proved to be an invaluable tool for the surgeon in guiding the approach to the surgical resection of the scar, successful reshaping of the ventricle with prevention of diastolic dysfunction, and the most appropriate late imaging to reassess $\mathrm{LV}$ remodeling at follow-up.

\section{References}

1. Figueras J, Alcalde O, Barrabés JA, Serra V, Alguersuari J, Cortadellas J, et al. Changes in hospital mortality rates in 425 patients with acute ST-elevation myocardial infarction and cardiac rupture over a 30-year period. Circulation. 2008;118:2783-9.

2. Becker RC, Gore JM, Lambrew C, Weaver WD, Rubison RM, French WJ, et al. A composite view of cardiac rupture in the United States National Registry of Myocardial Infarction. J Am Coll Cardiol. 1996;27:1321-6.

3. Gray H. Heart and mediastinum. In: Gray's Anatomy: The Anatomical Basis of Clinical Practice. 40th ed. Philadelphia, Pa: Churchill Livingstone Elsevier; 2008:2056.

4. Pope JH, Aufderheide TP, Ruthazer R, Woolard RH, Feldman JA, Beshansky JR, et al. Missed diagnoses of acute cardiac ischemia in the emergency department. $N$ Engl J Med. 2000;342:1163-70.

5. Baker GE, Koelmeyer TD. Death due to unrecognised myocardial infarction causing left ventricular rupture: can we improve the diagnostic rate? $N \mathrm{Z}$ Med J. 1999;112:429-30. 